\title{
Facilitators and barriers experienced by federal cross-sector partners during the implementation of a healthy eating campaign
}

\author{
Melissa Anne Fernandez ${ }^{1,2}$, Sophie Desroches ${ }^{1,2}$, Marie Marquis ${ }^{3}$, Mylène Turcotte ${ }^{1}$ and \\ Véronique Provencher ${ }^{1,2, *}$ \\ 'Institute of Nutrition and Functional Foods, Université Laval, Pavillon des Services, 2440 Hochelaga Blvd, Québec, \\ QC, Canada, GIC OA6: ${ }^{2}$ School of Nutrition, Université Laval, Québec, QC, Canada: ${ }^{3}$ Department of Nutrition, \\ Faculté de Medicine, Université de Montréal, Montréal, QC, Canada
}

Submitted 10 November 2016: Final revision received 14 April 2017: Accepted 17 May 2017: First published online 21 June 2017

\begin{abstract}
Objective: To identify facilitators and barriers that Health Canada's (HC) crosssector partners experienced while implementing the Eat Well Campaign: Food Skills (EWC; 2013-2014) and describe how these experiences might differ according to distinct partner types.

Design: A qualitative study using hour-long semi-structured telephone interviews conducted with HC partners that were transcribed verbatim. Facilitators and barriers were identified inductively and analysed according partner types.

Setting: Implementation of a national mass-media health education campaign.

Subjects: Twenty-one of HC's cross-sector partners (food retailers, media and health organizations) engaged in the EWC.

Results: Facilitators and barriers were grouped into seven major themes: operational elements, intervention factors, resources, collaborator traits, developer traits, partnership factors and target population factors. Four of these themes had dual roles as both facilitators and barriers (intervention factors, resources, collaborator traits and developer traits). Sub-themes identified as both facilitators and barriers illustrate the extent to which a facilitator can easily become a barrier. Partnership factors were unique facilitators, while operational and target population factors were unique barriers. Time was a barrier that was common to almost all partners regardless of partnership type. There appeared to be a greater degree of uniformity among facilitators, whereas barriers were more diverse and unique to the realities of specific types of partner.

Conclusions: Collaborative planning will help public health organizations anticipate barriers unique to the realities of specific types of organizations. It will also prevent facilitators from becoming barriers. Advanced planning will help organizations manage time constraints and integrate activities, facilitating implementation.
\end{abstract}

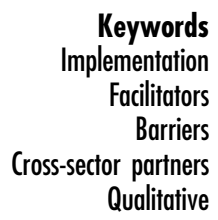

In Canada, child obesity was made a public health priority by Federal, Provincial and Territorial Ministers of Health in $2010^{(1)}$. The Eat Well Campaign: Food Skills (EWC) was an initiative that Health Canada (HC), a federal health agency, developed to address child obesity prevention by targeting dietary changes at the family level. The EWC was a multichannel mass-media health education campaign that used social marketing as a strategy to disseminate messages about family meal planning to Canadian parents. Dissemination of activities occurred over five activation periods (or phases) from March 2013 to March 2014 with the help of cross-sector partners (Fig. 1). Partnerships with the food retail industry, the media and health organizations were used to extend the reach of the campaign and leverage resources and expertise to enhance outcomes ${ }^{(2)}$. The nature of the partnerships included in-kind agreements with the food retail industry, paid contracts with the media, and both in-kind agreements and cost-sharing contracts with health organizations.

Cross-sector partnerships in health are becoming more common and considered necessary to address complex health issues like obesity ${ }^{(3)}$. Little is known about crosssector contributions to the implementation of nutrition interventions or partnership experiences in public health. Public-private partnerships, particularly with the food industry, have the potential to influence the public's choices about healthy food behaviours and they should be strategically approached ${ }^{(4)}$. It is important to study how 


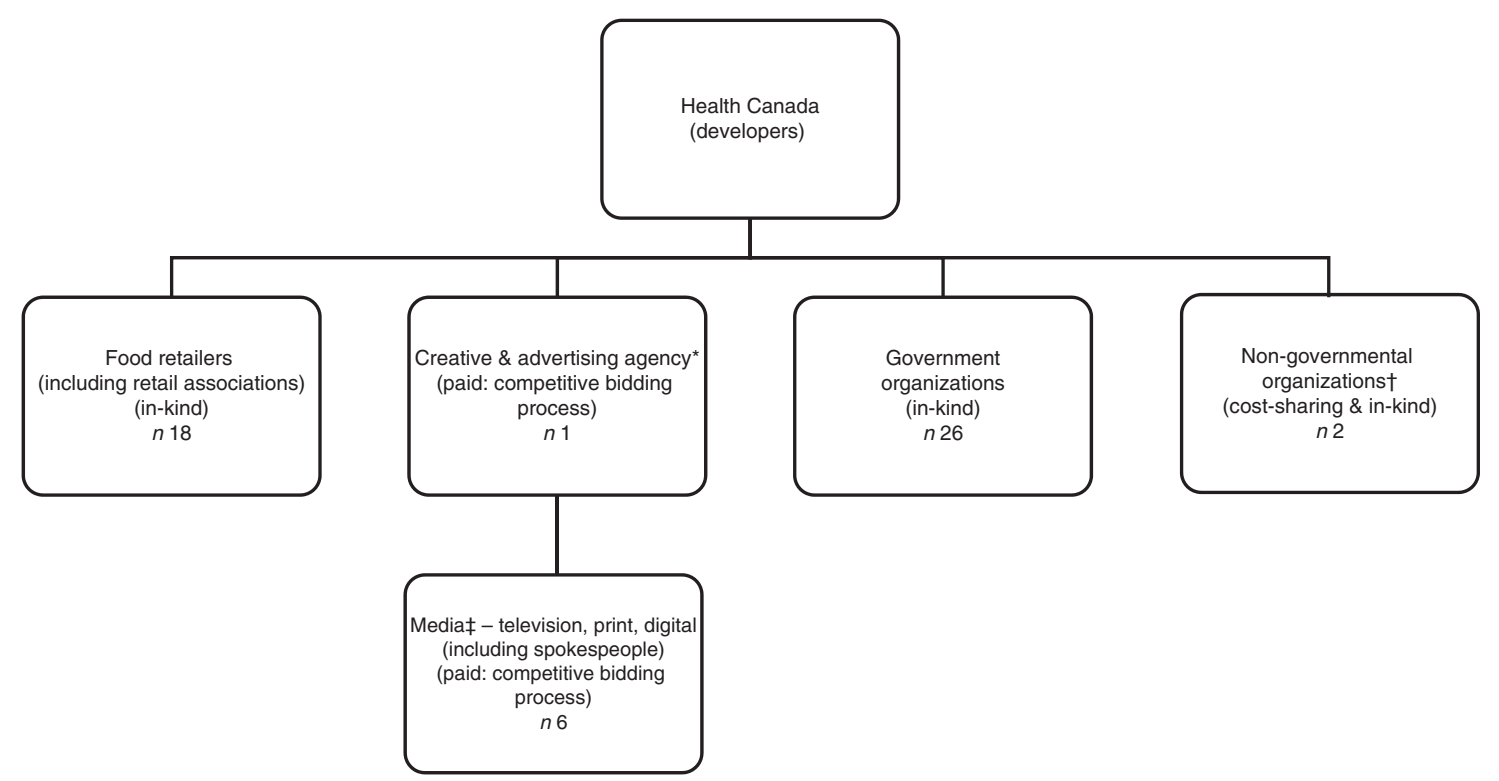

Fig. 1 The Eat Well Campaign: Food Skills collaboration. *The creative and advertising agency was an intermediary between individual food retailers, the media and Health Canada. †For reporting purposes, non-governmental organizations were combined with government organizations and are collectively called 'health organizations'. ‡For reporting purposes, media partners were combined with the creative and advertising agency and are collectively called the 'media'. (Reprinted with permission from Fernandez et al. $(2016)^{(9)}$ )

these partners interact together to implement a nutrition initiative. The effectiveness of an intervention is closely linked to the manner in which it is implemented ${ }^{(5,6)}$ and knowledge of implementation barriers in particular can enhance the understanding of avenues for outcome improvement ${ }^{(7)}$. However, few studies investigate facilitators of and barriers to implementation, which could provide valuable insight into the implementation process as well as identify intervention success factors ${ }^{(8)}$. The purpose of the present study was to: (i) identify facilitators and barriers experienced by HC's cross-sector partners during the implementation of the EWC; and (ii) describe similarities and differences in facilitators and barriers between cross-sector partner groups (food retailers, media and health organizations) and partner agreements (contractual $v$. in-kind).

\section{Methods}

\section{Partners and recruitment}

As previously mentioned, the EWC was implemented over five activation periods from March 2013 to March 2014 with fifty-three cross-sector partners ${ }^{(9)}$. The role and level of involvement of each partner varied, with paid and costsharing partners having defined roles as per contractual agreements and in-kind partners being involved voluntarily in various activities and phases of the campaign. The food retail industry included small and large food retailers and food retail associations. They promoted the campaign in-store, online and through grocery-store flyers. Media partners were involved in producing and promoting content for the campaign: televising vignettes, creating website content, print ads and editorials in magazines. Health organizations were involved primarily in developing and/or disseminating campaign materials through their regional networks.

The current study was part of a process evaluation to understand the implementation of the EWC among HC's cross-sector partners. Study execution and results reporting were conducted according to the thirty-two-item Consolidated criteria for reporting qualitative research $(\text { COREQ })^{(10)}$. A stratified purposeful sample ${ }^{(11)}$ of forty-one organizations was identified. Key informants at each organization were first identified by a manager at HC and then contacted by a trained bilingual interviewer (M.T.; registered dietitian, female, 36 years) by telephone and/or email prior to their interviews to invite them into the study. The purpose of the research was disclosed to all participants, signed written consent was obtained and the interview guide was provided to all participants by email prior to the interview. Interviews were conducted until data saturation was approached.

The interviewer (M.T.) conducted a semi-structured hour-long telephone interview (duration ranging from 45 to $88 \mathrm{~min}$; median duration $57 \mathrm{~min}$ ) with each participant, capturing information on experiences implementing the EWC. The interview questions were based on an integrated model of programme implementation ${ }^{(12,13)}$. Interviews were recorded and transcribed verbatim. Transcripts were not returned to participants, but were verified for accuracy by trained coders (M.A.F.; registered dietitian, female, 32 years or J.D.; anthropologist, female, 25 years). An initial codebook of facilitators and barriers was developed inductively by the lead coder (M.A.F.) and 
interviewer (M.T.) with key words from analytic memos of interview recordings. Using thematic content analysis ${ }^{(14)}$, three bilingual coders (M.A.F., M.T., J.D.) challenged the codebook by triple coding six contrasting interviews intermittently during the coding process to ensure intercoder agreement was maintained throughout. After each triple-coded interview, new themes and changes to existing parent themes were validated together before proceeding to simple coding. Parent themes were subsequently split ${ }^{(15)}$ into sub-themes by the lead coder (M.A.F.) and the interviewer (M.T.) corroborated the most complex sections of interview text. Sub-analyses of themes were also conducted according to partner group (food retailer, media and health organization) and partnership agreement (contractual $v$. in-kind). It was not possible to validate themes with individual participants as results were reported collectively by partner type; however, findings were corroborated with HC. To maintain confidentiality of organizations, specific details of activities, identities and location were omitted from quotes. To focus on the most salient themes, only those reported by three or more respondents were analysed.

\section{Results}

Twenty-two organizations accepted to participate; one health organization withdrew from the study resulting in twenty-one completed interviews with eight food retailers, six media and seven health organizations. The key informants representing organizations were a mix of dietitians, public health practitioners, marketing representatives and communication experts that worked either on a regional or national level in Canada. Characteristics of the organizations that participated in the study are described in Table 1.

Seven major themes were identified and are listed in Table 2 with the number of organizations that spoke of each respective theme. Facilitating factors were identified by all partners except for one of the health organizations. The major facilitating themes that emerged were: (i) resources; (ii) collaborator traits; (iii) intervention factors; (iv) developer traits; and (v) partnership factors (Table 2). Sub-themes and examples are listed in Table 3 in decreasing order of frequency. All respondents mentioned diverse barriers related to the implementation of the EWC. The major barriers identified were grouped into six major themes: (i) operational elements; (ii) intervention factors; (iii) resources; (iv) target population factors; (v) developer traits; and (vi) collaborator traits (Table 2). Sub-themes and examples are listed in Table 4 in decreasing order of frequency. Intervention factors, resources, partnership factors and developer traits had dual roles as both facilitators and barriers. Major facilitating themes appeared to be homogeneous and equally experienced, whereas barriers appeared to be slightly more diverse and unique to specific groups of partners.
Table 1 Key characteristics of the twenty-one participating organizations, Health Canada's Eat Well Campaign partners, 2013-2014

\begin{tabular}{lcc}
\hline Characteristic & $n$ & $\%$ \\
\hline Type of agreement & & \\
$\quad$ Contractual (paid or cost-sharing) & 7 & 33 \\
$\quad$ In-kind agreements (volunteer) & 14 & 67 \\
Regional activity ${ }^{\dagger} \dagger$ & & \\
National & 8 & 38 \\
Most Provinces and Territories & 2 & 10 \\
West Coast and Prairies & 3 & 14 \\
Central Canada & 4 & 19 \\
Maritimes or Far North & 4 & 19 \\
\hline
\end{tabular}

${ }^{*}$ Regional definitions: West Coast $=$ British Columbia; Prairies =Alberta, Saskatchewan and Manitoba; Central Canada=Ontario and Québec; Maritimes $=$ Newfoundland and Labrador, New Brunswick, Nova Scotia and Prince Edward Island; Far North = Yukon Territory, Northwest Territory and Nunavut.

†Some groups were combined to maintain the confidentiality of easily identifiable participants.

\section{Operational elements}

Barriers that related to the regular functioning of the organization were clustered under the theme 'operational elements'. This theme included all barriers involving time, campaign integration into organizations' planned activities and restrictions to mandates that prevented optimization of intended activities. There were no facilitating factors related to this theme. This theme represented the most prominent implementation challenges, and time was a salient barrier that was universally experienced by nearly all partners interviewed. The majority of food retailers and a minority of health organizations (i.e. in-kind partners) also mentioned that activity implementation was time intensive:

'Too much time for what our business is about. There's too much time involved.' (Food retailer)

This barrier, however, was not an issue for contractual partnerships, presumably because paid partners expected campaign activities to take up a certain amount of time and resources. Although partners in all groups mentioned difficulties implementing activities under a tight timeline and long delays from $\mathrm{HC}$ delivering materials or approvals resulting in changes or alterations to planned activities, this barrier was particularly challenging for the media:

'Health Canada never managed to give us the information in time.' (Media)

The majority of food retailers and health organizations involved in in-kind agreements experienced conflicts integrating EWC activities within existing organizational plans, which challenged the implementation of the EWC:

'The challenge would be trying to fit a campaign into a specific period of time, around specific messaging that may or may not fit with the broader communication strategy at that point in time. We may be talking about getting ready for Thanksgiving at the 
Table 2 Major themes identified by different groups of cross-sector partners as facilitators and barriers to the implementation of the Eat Well Campaign: Food Skills (2013-2014), Canada

\begin{tabular}{|c|c|c|c|c|c|c|c|c|}
\hline & \multicolumn{4}{|c|}{ Facilitators ( $\left.n_{\text {sources }} 20\right)$} & \multicolumn{4}{|c|}{ Barriers ( $\left.n_{\text {sources }} 21\right)$} \\
\hline & FR & M & $\mathrm{HO}$ & Total & FR & M & $\mathrm{HO}$ & Total \\
\hline Operational elements & 0 & 0 & 0 & 0 & 8 & 6 & 6 & 20 \\
\hline Intervention factors & 8 & 6 & 3 & 17 & 7 & 6 & 6 & 19 \\
\hline Resources & 6 & 6 & 6 & 18 & 8 & 3 & 6 & 17 \\
\hline Partnership factors & 6 & 6 & 5 & 17 & 0 & 0 & 0 & 0 \\
\hline Developer (Health Canada) traits & 6 & 5 & 5 & 16 & 5 & 6 & 3 & 14 \\
\hline Collaborator traits & 5 & 6 & 5 & 16 & 6 & 2 & 4 & 12 \\
\hline Target population factors & 0 & 0 & 0 & 0 & 5 & 5 & 6 & 16 \\
\hline
\end{tabular}

FR, food retailers; M, media; $\mathrm{HO}$, health organizations.

Table 3 Descriptions of themes and sub-themes that emerged as facilitating factors for cross-sector partners during the implementation of the Eat Well Campaign: Food Skills (EWC; 2013-2014), Canada

\begin{tabular}{|c|c|c|}
\hline Themes and sub-themes & Description & No. of partners \\
\hline Resources & & 18 \\
\hline Material resources & $\begin{array}{l}\text { Good-quality or attractive posters, visuals, information sheets and advertising } \\
\text { resources }\end{array}$ & 16 \\
\hline Financial resources & Adequate budgets allocated to execute activities & 9 \\
\hline Human resources & Sufficient and competent staff available to execute activities & 5 \\
\hline Intervention factors & & 17 \\
\hline Nature of the campaign & $\begin{array}{l}\text { The positive, easy-going, socially acceptable messages made the campaign } \\
\text { easy to promote }\end{array}$ & 15 \\
\hline Organized & Activities were well organized and planned & 6 \\
\hline Easy work & The activities were easy to implement & 5 \\
\hline Subsequent phases easier & The second and subsequent phases were easier to implement than the first & 4 \\
\hline Partnership factors & & 16 \\
\hline Good relationship & Good working relationships between collaborators made implementation easier & 10 \\
\hline Collaboration & Many organizations working together to advance the same objective & 9 \\
\hline Positive experience & Being involved in the Eat Well Campaign was a good experience for partners & 8 \\
\hline Worked together before & Having previous work experience with Health Canada made implementation easier & 5 \\
\hline Excellent liaison & Having a liaison made working with Health Canada easier & 3 \\
\hline Developer (Health Canada) traits & & 16 \\
\hline Good communicators & Essential information communicated at appropriate times and feedback provided & 12 \\
\hline Nice, helpful, polite & Health Canada's staff were pleasant & 5 \\
\hline Flexible and supportive & Health Canada provided support for activity implementation and gave partners flexibility & 5 \\
\hline Trusting & Gaining Health Canada's trust was important & 3 \\
\hline Collaborator traits & & 16 \\
\hline $\begin{array}{l}\text { Understanding and } \\
\text { accommodating }\end{array}$ & Sympathetic, tolerant and forgiving of inconveniences, obliging and cooperative & 11 \\
\hline Committed & Dedication to campaign implementation & 10 \\
\hline Philanthropic nature & Generous and benevolent, interested in the welfare of clients/population & 7 \\
\hline Trusted source & Partners were a reputable source of information and expertise & 4 \\
\hline
\end{tabular}

same time as Health Canada was talking about getting back to school.' (Food retailer)

Having a restrained operational mandate and limited capacity to implement activities was perceived as a barrier for a minority of respondents across partner groups:

'Of course with a bigger piece of the pie, I think we could have done something bigger and more comprehensive.' (Media)

\section{Intervention factors}

'Intervention factors' was defined as all elements intrinsic to the EWC that created barriers or were facilitating factors for implementation. Overall, the nature of the campaign (i.e. health oriented and positive messages) was seen as a major facilitator across partner groups and this theme appeared to be extremely prominent among the media and food retailers:

'Because it's an important topic there's so many different ways that you can target or teach people.'

(Media)

Facilitating intervention factors that characterized the EWC were organized, overall simple to implement, and it was believed that second and subsequent phases of the EWC were easier than the initial activation period:

'The first one came a little quickly, but once we got into the rhythm of it I think the other ones were fine, because at that point we already knew what to expect.' (Food retailer) 
Table 4 Descriptions of themes and sub-themes that emerged as barriers for cross-sector partners during the implementation of the Eat Well Campaign: Food Skills (2013-2014), Canada

\begin{tabular}{|c|c|c|}
\hline Themes and sub-themes & Description & $\begin{array}{l}\text { No. of } \\
\text { partners }\end{array}$ \\
\hline Operational elements & & 20 \\
\hline Time & Delays, tight timelines and time-consuming activities & 19 \\
\hline Integration conflicts & Difficulties integrating campaign activities into organizational plans & 12 \\
\hline Restrained mandate & Limitations to contracts and agreements that prevented the best implementation of activities & 4 \\
\hline Intervention factors & & 19 \\
\hline Issues with strategy & Criticism of the appropriateness of the campaign strategy & 12 \\
\hline Ineffective messaging & Criticism and doubts over the ability for campaign messages to break through to the audience & 8 \\
\hline Visibility & Some campaign elements were not adequately promoted & 7 \\
\hline Activity maintenance & $\begin{array}{l}\text { Could not continue activities or had to reduce extent of implementation in second and } \\
\text { subsequent phases of the campaign }\end{array}$ & 5 \\
\hline Resources & & 17 \\
\hline Financial resources & Inadequate or no budget allocated to the campaign & 13 \\
\hline $\begin{array}{l}\text { Human resources } \\
\text { and expertise }\end{array}$ & Inadequate staff allocated to the campaign & 9 \\
\hline Material & Materials not adapted to population or not in an appropriate/usable format & 4 \\
\hline Target population factors & & 16 \\
\hline Audience segmentation & Differences within the population & 8 \\
\hline Level of readiness & Population may not be open to campaign messages and behaviour change & 6 \\
\hline Time restrictions & Parents have busy schedules and might not have time to change behaviours & 5 \\
\hline Affordability & Perceptions that healthy eating is not affordable & 4 \\
\hline Lack of knowledge & Parents might not have enough knowledge to make changes & 4 \\
\hline Developer traits & & 14 \\
\hline Demanding work & $\begin{array}{l}\text { Tough approval process, rigidity or processes, control of information, changes to mandates } \\
\text { and directions }\end{array}$ & 10 \\
\hline Poor communicators & Communication gaps, inefficient communication, little or no direct contact with Health Canada & 9 \\
\hline Collaborator traits & & 12 \\
\hline Frustrated & Expressions or disappointment or annoyance about activity implementation & 7 \\
\hline Flyer space constraints & Competition with valuable advertising space & 5 \\
\hline Political constraints & Government politicizes or programming that prevented implementation of activities & 3 \\
\hline $\begin{array}{l}\text { Reservations working with } \\
\text { competitors }\end{array}$ & Difficulties working collaborating with competitors & 3 \\
\hline
\end{tabular}

More than half of partners across groups had issues with the intervention strategy used by HC. For example, partners questioned the choice of channels used to diffuse the campaign (e.g. traditional $v$. social media). Partners felt that the EWC did not appear to have a concrete intervention and that it was not interactive. HC was criticized for trying to implement too many activities and for not taking social determinants into account:

'I suppose I could adapt the content for [our population], but, you know I shouldn't have to adapt everything. I mean it's not just white people that live in Canada, right?' (Health organization)

Furthermore, half the food retailers and media respondents as well as a minority of health organizations believed that the EWC messaging was not interesting or effective enough to break through noise around health messages and grab the public's attention to effect behaviour change:

'So there's innovative in terms of the creative, so yes, the creative was good creative, but to me innovative means that there's something about it that's going to break through and be compelling, and in helping consumers to make different choices. But, I think in general, the Eat Well Campaign was just another education campaign.' (Food retailer)
The majority of media respondents and a minority of both food retailers and health organizations felt that poor campaign visibility was a major challenge:

'Yeah, but did it really reach enough people? It wasn't because of a lack of interest ... It's more that the campaign wasn't visible enough to impact many people, you know.' (Media)

In-kind partners were the only ones to experience challenges around commitments to implement foreseen campaign activities consistently over multiple phases throughout the year. The multiple activation periods of the campaign made it difficult for in-kind partners to maintain implementation throughout the year, resulting in what appears strong activation at the start of the campaign and fewer activities being carried out for subsequent phases of the campaign:

'It is extremely expensive to get visibility, we have a large network to cover, so we did [the activity] once for Health Canada, and then we didn't repeat [the activity].' (Food retailer)

\section{Resources}

Material resources was a prominent facilitating theme for all groups of partners. Respondents spoke positively about 
the EWC resources as being high-quality, ready-to-use good tools that were practical:

'The aspect of developing a campaign with really nice visual content, it's what sets itself apart from other campaigns. I think it's the [EWC's] strength; the quality of the materials produced.' (Media)

Human resources that facilitated implementation included making support staff available, having specific expertise in line with the EWC and a good fit between key staff and the EWC. Financial resources were a facilitating factor for a minority of partners in each group. Only food retailers spoke of their organizations allocating a budget as being a facilitator, whereas a minority of respondents from each group of partners felt that HC subsidizing costs, for example by providing material resources, was a facilitating factor:

'Health Canada was funding the development of the artwork [...] and they helped fund a lot of base costs and then we also paid for production and materials and distribution and added support and staff and that type of thing. So it was a jointly funded programme.' (Food retailer)

On the other hand, limited financial resources were experienced by nearly all food retailers, the majority of health organizations and half of the media respondents:

'Of course we could have done more, but with the budget we had ... we tried to do the best that we could.' (Food retailer)

Respondents spoke about having to make extra investments, absorb activity costs, having a limited or no budget, and having to make trade-offs between choosing to invest in EWC activities over other initiatives. Limited human resources and expertise were mentioned by half the food retailers and health organizations and a minority of media respondents. Specific challenges included the lack of manpower and expertise, poor staff fit and issues managing staff. In-kind partners mentioned challenges regarding the materials provided by HC not being in a usable format to meet their needs or not having the capacity to adapt materials for their clients/ public:

'We don't really have the manpower here to do all that [adapt resources]. I'd really like it if people [Health Canada] could help us out.' (Health organization)

\section{Partnership factors}

Partnership factors emerged only as facilitating factors. A good relationship with HC, collaborative effort and a positive experience were facilitators described across partner groups:
'I think we have a very good relationship with Health Canada. Certainly part of our mandate is partnerships. I think [our organization] really sees the benefits of participating in partnerships [...] the end result is bigger than the effort that you put in when you partner with someone else.' (Health organization)

Having worked with $\mathrm{HC}$ in the past was a facilitator for some media and health organizations:

'I'm pretty sure that it went much smoother, because we knew we had a process [from working together previously] ... and we could manage their expectations better.' (Media)

The use of a creative and advertising liaison, contracted by HC, was described as a facilitator only by media partners.

\section{Developer traits}

Overall, HC's ability to ensure good communication was an important facilitator among partner groups, particularly for food retailers and the media. Examples of strong communication mentioned included providing positive feedback and making itself very available:

'They gave us really good positive feedback on the content we were delivering, and that they liked it and they thought it was relevant and great. So, there was sort of a positive reinforcement. I think, that was really good.' (Media)

A minority of partners also portrayed HC's nice, helpful and polite nature as a facilitating factor. Only in-kind partners described HC as being supportive and flexible of implementation activities and its expectations of partners' contributions. In addition, the establishment of trust with HC as being a facilitator was mentioned only by media partners:

'In the end, there was really mutual trust, and in the end, they knew that if we showed up, it was going to be great.' (Media)

Almost half of the respondents mentioned difficulty having to work under HC's demanding parameters: tough approval process, rigidity and changes to mandates. The approval process was a major implementation barrier for all partner groups, especially all members of the media. Last-minute changes to mandates were big challenges only for the media. In addition, all media partners and a minority of food retailers expressed a high level of rigidity from $\mathrm{HC}$ with regard to control over messaging and details of campaign activities:

'Health Canada sort of came back with more and more strict guidelines about what we could and couldn't say.' (Food retailer)

Partners in every group mentioned communication issues. Partners felt that the conference-style communication with 
HC was inefficient. Some media and food retailers felt that they had little to no direct contact with HC. Finally, communication gaps were major challenges for half the food retailers and media respondents and some health organizations:

'They weren't necessarily sharing details of the campaign and how the campaign was going to roll out. We knew that the food retailers were participating, because we saw in the grocery stores [...] not necessarily, because we'd been told by Health Canada.' (Health organization)

\section{Collaborator traits}

Accommodating, committed, philanthropic nature and trusted source were the sub-themes identified as facilitating collaborator traits; whereas frustrated, political issues, limited flyer space and issues working with competitors were collaborator traits that were barriers to implementation. The strong perceived level of commitment and implication of food retailers and the media were considered an important facilitating factor:

'I think they were equally motivated to see this campaign succeed, and so were actively involved and well-resourced, yeah.' (Food retailer)

Some health organizations and media spoke of their reputation as trusted sources of health information:

'We are trusted, well respected so ... you know it [EWC partnership with HC] just makes sense.' (Health organization)

A few respondents from each group felt frustrated and expressed disappointment regarding the EWC implementation:

'I guess because there wasn't a lot of promotion done by Health Canada in our region, that even with all that we did, it still fell a little short.' (Food retailer)

Food retailers experienced unique challenges, such as running the same campaign as a major competitor and constraints for flyer space to promote the EWC over paid adverts for product placement:

'It's a tough sell, because a flyer is to promote food and food products and this was more messaging, and even when we have our own programmes around health and wellness, we struggle to find space in the flyer to promote them.' (Food retailer)

Political constraints over health messaging priorities were uniquely expressed by health organizations:

'Politically, the communications division was unable to participate actively.' (Health organization)

\section{Target population factors}

Audience segmentation was a barrier to implementing the EWC that was mentioned by a minority of food retailers, media respondents and a majority of health organizations. The target population was segmented in terms of preferences for local media content $v$. mainstream massmedia content, traditional media $v$. social media, and different regional realities across the country:

'It's such a challenge to disseminate anything across Canada, to so many people, so I just think that what Health Canada has done in terms of dissemination is more than they have ever done, but it's still a challenge. You still talk to people like health professionals that don't know about it. So, it's just the nature of the size of Canada more than anything.' (Health organization)

Food retailers and the media spoke about the target population's lack of readiness to make dietary changes, lack of time, perceptions about the affordability of healthy foods and lack of knowledge as barriers to their responsiveness:

'Not everyone is ready to change, not everyone wants to change [...] you can't please everyone.' (Media)

\section{Discussion}

Overall, many of the facilitators and barriers that emerged in the present study (e.g. communication, resources and time) have also been identified in programme implementation literature ${ }^{(13,16)}$ suggesting that, regardless of implementation context, similar themes are likely to emerge. This observation may help anticipate certain commonly experienced challenges which can be taken into account during collaborative intervention planning.

Many similar barriers and facilitators were experienced across partner groups despite differences in their relationships with HC. Furthermore, similar themes (e.g. resources and communication) emerged as both barriers and facilitators. HC's capacity as a strong communicator was a facilitating factor that emerged from interviews with all partner groups and has been identified as a key implementation success factor for various interventions ${ }^{(17,18)}$. Communication can be an important facilitator for implementation and building strong partnerships ${ }^{(13)}$. However, poor communication can cause frustration and limit partners' ability to maintain or implement an intervention. Organizations should dedicate resources to keeping their partners informed, providing feedback and maintaining an open flow of communication in a consistent manner with all partners.

The most prominent facilitating theme was the material resources that HC provided to its partners. Moreover, having adequate human resources was identified as a facilitator for 
both the media and health organizations. Having access to adequate resources (material and human) is often identified as a facilitator in implementation evaluations, whereas inadequate resources is an impediment ${ }^{(18)}$. The nature of the campaign was another prominent facilitating factor for food retailers and media respondents. This finding indicates that regardless of whether a partnership is in-kind or contractual, partners are likely to be more open when the topic of the initiative is a cause that is universally valued by the organization ${ }^{(19)}$. The nature of the EWC may have played a role in influencing organizations' level of commitment and implication to its activities, particularly when the company's values and/or mission align with campaign objectives, which is supported by the strong relationship between compatibility of an innovation and its assimilation within an organization ${ }^{(20)}$.

Two themes emerged as being completely unique to the media: trust of HC and working with an excellent liaison. The importance to media of being trusted by HC may be a reflection of media's capacity to maintain good working relationships while working under tough parameters. This aligns with the finding that partnership factors were extremely important facilitators for the media including working collaboratively, having a positive partnership experience and previous experience working with HC. Furthermore, particular personality traits such as the media's understanding and its flexibility were likely to facilitate tough working parameters, especially during changes to mandates. These findings are backed by expert agreement that public-private partnerships need to be governed by mutual trust and respect, which are key to ensuring transparency and open communication allowing for collaborations to succeed ${ }^{(19)}$.

Contrary to the EWC adoption ${ }^{(9)}$, barriers were more prominent during the implementation process. Elements that had either facilitated (e.g. social participation) or challenged (e.g. strict control of information by HC) the organizational adoption of the $\mathrm{EWC}^{(9)}$ re-emerged during implementation, reinforcing the strong connection between adoption and implementation and their potential impacts on reach and effectiveness ${ }^{(6)}$. Other qualitative studies have highlighted the importance of taking into consideration the contextual nature of factors associated with healthy eating programme and policy implementation $^{(21-23)}$. Granular-level analysis of sub-themes revealed salient differences between partner groups that are contextual in nature and are particularly important given the setting of an intervention implemented by cross-sector partners. For example, food retailers experienced challenges regarding dedicating flyer space and working with their competitors, whereas media respondents were the only ones to mention issues with mandate changes and health organizations were alone to speak of political issues. These differences between partners demonstrate that models for private-public partnerships cannot be onesize-fits-all and should be flexible enough to cater to the different realities of organizations from multiple sectors ${ }^{(3)}$. Working in close collaboration with cross-sector implementers can assist in addressing solutions to overcome barriers, ensuring optimized execution of an initiative ${ }^{(8)}$. Pre-intervention discussions and advanced planning can help anticipate contextual barriers by gaining a strong knowledge of partners' realities. Collaborative planning can even help avoid unique barriers particular to specific partners and reduce the likelihood that commonly experienced facilitators become barriers.

The primary barriers experienced by all partners related to time, the intervention strategy and having limited financial resources. Time was the most prominent theme for all partners, providing an indication of the importance of advance planning regardless of the type of organization. Both time ${ }^{(24-27)}$ and financial resources ${ }^{(28-30)}$ are known and very common barriers to intervention implementation often experienced at both the organizational and user levels. There appears to be a need for strategies to help organizations minimize time- and cost-related barriers to cross-sector partnerships with health agencies. Even though nearly all partners mentioned time as a major barrier to implementation, the nature of the challenge differed according to partner group and/or partnership agreement; in-kind partners spoke about the timeintensive nature of the mandate whereas delays and tough timelines were mainly issues for the media and health organizations. A large majority of partners cited issues with the intervention strategy used by HC. The EWC was a one-off campaign; however, had it been a programme, the perceived lack of intervention support could translate to the rejection or discontinuance of the innovation, potentially impacting the capacity for maintenance of a longer-term intervention ${ }^{(31)}$. Collaborative planning and strong communication to help partners understand the intervention strategy and rationale can be potential solutions not only for overcoming this type of barrier, but also to leverage partners' expertise to find alternative or more appropriate strategies.

For health organizations, audience segmentation appeared to be a concern for intervention implementation. The vast geographic expanse, different regional realities with regard to health needs and variable access to media in Canada are a major challenge for any kind of national intervention. From a social marketing perspective, segmenting an audience to determine which groups to target for an intervention and subsequently tailoring it to meet their needs is a strategic standard; however, this type of strategy involves considerable resources ${ }^{(32)}$. Nevertheless, in contexts where massmedia access may be variable, there are potential ethical considerations of using a non-segmented approach, which may inadvertently exclude segments with less knowledge and further promote health disparities ${ }^{(33)}$. For one health organization in particular, mass-media access was a major impediment to the adoption of the $\mathrm{EWC}^{(9)}$, which turned into a challenge during implementation and concern that a 
non-segmented approach could exacerbate health inequities and exclude populations that were not part of the mainstream target audience. The risks and benefits of employing a segmented approach would need to be carefully weighed. It is important that interventions adopt the full scope of criteria to effectively implement a social marketing campaign $^{(34)}$. The intervention strategy was strongly critiqued by partners, which is understandable given that the intervention's main strategy (social marketing) did not appear to adhere to recommended benchmark criteria laid out by experts $^{(35,36)}$. It was not clear to partners that the campaign sought to change behaviour, the prime objective of social marketing, or whether it was just 'another education campaign'. Furthermore, partners' perceptions of poor campaign visibility indicate that the marketing mix criteria may not have been adequately addressed for the EWC.

As mentioned previously, collaborative planning can anticipate and minimize barriers. While all collaborators were defined as 'partners', there was a major distinction in their involvement depending on the type of their agreement

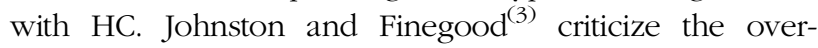
generalization of all types of collaborations as 'partnerships' when there is no shared decision making or planning involved in the relationship, and suggest the use of 'publicprivate interaction or engagement'. The later term better describes many of HC's partners, particularly those involved in in-kind agreements. To improve future interventions, it is important to define the extent of partnerships, their roles and engage them in shared decision making. These actions may help achieve greater alignment between the private and public sector, facilitating implementation for all parties involved, and ultimately leveraging partners' expertise to increase the reach and effectiveness of an intervention ${ }^{(3)}$.

The authors are confident that data saturation was approached as no new information came from additional interviews. Due to small sample size and easy identification of highly recognizable organizations, we had to group participants into partner groups (food retailers, media and health organizations) and describe experiences collectively, resulting in a loss of data richness from the unique experiences of individual organizations. On the other hand, the identification of high-level themes and sub-themes, particularly those that were experienced across partner groups and those with strong dualities, are likely to be applicable to a wide range of government cross-sector partners in various settings and are not just contextual facilitators and barriers specific to the implementation of the EWC.

\section{Conclusion}

Many barriers identified mirrored facilitators, and implementation of cross-sector initiatives could be enhanced by focusing on strengthening universally experienced elements (i.e. resources and communication). Strategies to overcome recurrent known barriers such as time are needed to optimize intervention implementation. Crosssector partners have different organizational realities and will likely experience unique types of barriers. The effectiveness of an intervention could theoretically be optimized through engaging cross-sector partners in collaborative planning prior to implementation in order to foresee and address strategies to overcome potential barriers. In particular, the following proactive points are recommended for public health organizations engaging in cross-sector partnerships.

- The importance of strong communication during all phases of implementation is not to be underestimated. Communication can be a strength when well executed, but communication gaps can seriously hinder effective and efficient implementation. Furthermore, poor communication or communication gaps can lead to unnecessary frustration and feelings of neglect. Consistent and appropriate communication throughout an intervention should include timely notices of changes to mandates, regular updates and feedback about performance and outcomes.

- Participatory planning of interventions is crucial when working in partnership, and it is particularly relevant for cross-sector collaborations where realities and resources of the parties involved may differ considerably. Participatory planning will prevent facilitators from turning into barriers and help anticipate barriers associated with specific types of partners. Furthermore, partners from different sectors likely have specific expertise that can be leveraged to optimize intervention strategies and outcomes. Therefore, including partners in intervention planning may minimize wasted time and resources during implementation.

- Advanced planning and prior agreements could help avoid unintended cessation of activities and facilitate the integration of an intervention within an organization. When engaging in-kind collaborations with cross-sector partners, it is necessary to understand their individual realities in terms of level of commitment, material and financial resources, competing interests and organizational capacity.

\section{Acknowledgements}

Acknowledgements: The authors thank HC for its collaboration, J.D. for help with analysis and participants for their time. Financial support: This study was funded by a grant by the Canadian Institutes of Health Research (CIHR; funding reference number GIR-127078). CIHR had no role in the design, analysis or writing of this article. S.D. is a CIHR New Investigator. M.A.F. is a CIHR fellow and a recipient of a scholarship from l'Observatoire de l'offre alimentaire. Conflict of interest: The authors declare that they have no competing interests. Authorship: M.A.F. developed the data analysis methodology, analysed the 
data and wrote the manuscript. S.D. and V.P. were involved in developing the study design, development of the data analysis methodology and corroborating methods. M.M. was involved in developing the study design and corroborating methods. M.T. was involved in data collection and data analysis. All authors were involved in reviewing and editing the manuscript. Ethics of human subject participation: This study was conducted according to the guidelines laid down in the Declaration of Helsinki and all procedures involving human subjects were approved by the Comité d'éthique de la recherche avec les êtres humains de l'Université Laval (\# 2013-055) and the Comité d'éthique de la recherche en santé de Université de Montréal (\#13-118-CERES-R) research ethics committees. Written and informed consent was obtained from all participants. As per participant consent, confidentiality was maintained by modifying or omitting gender, number, region and language identifiers in excerpts reported.

\section{References}

1. Public Health Agency of Canada (2010) Curbing Childhood Obesity: An Overview of the Federal, Provincial and Territorial Framework for Action to Promote Healthy Weights. Ottawa: PHAC.

2. Health Canada (2013) Healthy Eating and Education Awareness Initiative: Phase 3 - Healthy Eating and Healthy Weights: A Focus on Food Skills to Support Healthy Eating and Healthy Weights. Ottawa: Health Canada.

3. Johnston LM \& Finegood DT (2015) Cross-sector partnerships and public health: challenges and opportunities for addressing obesity and noncommunicable diseases through engagement with the private sector. Annu Rev Public Health 36, 255-271.

4. Hawkes C \& Buse K (2011) Public health sector and food industry interaction: it's time to clarify the term 'partnership' and be honest about underlying interests. Eur J Public Health 21, 400-401.

5. Tseng M \& Nazmi A (2015) Programmes, policies and implementation. Public Health Nutr 18, 1526-1527.

6. Glasgow RE, Lichtenstein E \& Marcus AC (2003) Why don't we see more translation of health promotion research to practice? Rethinking the efficacy-to-effectiveness transition. Am J Public Health 93, 1261-1267.

7. Glasgow RE, Klesges LM, Dzewaltowski DA et al. (2006) Evaluating the impact of health promotion programs: using the RE-AIM framework to form summary measures for decision making involving complex issues. Health Educ Res 21, 688-694.

8. van Nassau F, Singh AS, van Mechelen W et al. (2015) Implementation evaluation of school-based obesity prevention programmes in youth; how, what and why? Public Health Nutr 18, 1531-1534.

9. Fernandez M, Desroches S, Turcotte M et al. (2016) Factors influencing the adoption of a healthy eating campaign by federal cross-sector partners: a qualitative study. $B M C$ Public Health 16, 904.

10. Tong A, Sainsbury P \& Craig J (2007) Consolidated criteria for reporting qualitative research (COREQ): a 32-item checklist for interviews and focus groups. Int $J$ Qual Health Care 19, 349-357.

11. Palinkas LA, Horwitz SM, Green CA et al. (2015) Purposeful sampling for qualitative data collection and analysis in mixed method implementation research. Adm Policy Ment Health 42, 533-544.

12. Berkel C, Mauricio AM, Schoenfelder E et al. (2011) Putting the pieces together: an integrated model of program implementation. Prev Sci 12, 23-33.

13. Dreisinger ML, Boland EM, Filler CD et al. (2012) Contextual factors influencing readiness for dissemination of obesity prevention programs and policies. Health Educ Res 27, 292-306.

14. Braun V \& Clarke V (2006) Using thematic analysis in psychology. Qual Res Psychol 3, 77-101.

15. Saldaña J (2013) The Coding Manual for Qualitative Researchers, 2nd ed. Los Angeles, CA: SAGE Publications, Inc.

16. Sopcak N, Aguilar C, O'Brien MA et al. (2016) Implementation of the BETTER 2 program: a qualitative study exploring barriers and facilitators of a novel way to improve chronic disease prevention and screening in primary care. Implement Sci 11, 158.

17. Newton PJ, Davidson PM, Halcomb EJ et al. (2007) Barriers and facilitators to the implementation of the collaborative method: reflections from a single site. Qual Saf Health Care 16, 409-414.

18. Heslehurst N, Newham J, Maniatopoulos G et al. (2014) Implementation of pregnancy weight management and obesity guidelines: a meta-synthesis of healthcare professionals' barriers and facilitators using the Theoretical Domains Framework. Obes Rev 15, 462-486.

19. Alexander N, Rowe S, Brackett RE et al. (2015) Achieving a transparent, actionable framework for public-private partnerships for food and nutrition research. Am J Clin Nutr 101, 1359-1363.

20. Greenhalgh T, Robert G, Macfarlane F et al. (2004) Diffusion of innovations in service organizations: systematic review and recommendations. Milbank $Q$ 82, 581-629.

21. Fitzgerald S, Geaney F, Kelly C et al. (2016) Barriers to and facilitators of implementing complex workplace dietary interventions: process evaluation results of a cluster controlled trial. BMC Health Serv Res 16, 139.

22. Ardzejewska K, Tadros R \& Baxter D (2013) A descriptive study on the barriers and facilitators to implementation of the NSW (Australia) Healthy School Canteen Strategy. Health Educ J 72, 136-145.

23. Hall WJ, Schneider M, Thompson D et al. (2014) School factors as barriers to and facilitators of a preventive intervention for pediatric type 2 diabetes. Transl Behav Med 4, 131-140.

24. Dora M, Kumar M \& Gellynck X (2016) Determinants and barriers to lean implementation in food-processing SMEs - a multiple case analysis. Prod Plan Control 27, 1-23.

25. Justice LM, Logan JR \& Damschroder L (2015) Designing caregiver-implemented shared-reading interventions to overcome implementation barriers. J Speech Lang Hear Res 58, issue 6, S1851-S1863.

26. Liu HM, Laba TL, Massi L et al. (2015) Facilitators and barriers to implementation of a pragmatic clinical trial in Aboriginal health services. Med J Aust 203, 24-27.

27. Glenton C, Colvin CJ, Carlsen B et al. (2013) Barriers and facilitators to the implementation of lay health worker programmes to improve access to maternal and child health: qualitative evidence synthesis. Cochrane Database Syst Rev issue 10, CD010414.

28. Ramsey A, Lord S, Torrey J et al. (2016) Paving the way to successful implementation: identifying key barriers to use of technology-based therapeutic tools for behavioral health care. J Behav Health Serv Res 43, 54-70.

29. Kruse CS, Regier V \& Rheinboldt KT (2014) Barriers over time to full implementation of health information exchange in the United States. JMIR Med Inform 2, e26.

30. Kates SL, O'Malley N, Friedman SM et al. (2012) Barriers to implementation of an organized geriatric fracture program. Geriatr Orthop Surg Rehabil 3, 8-16. 
31. Rogers EM (2003) Diffusion of Innovations, 5th ed. New York: The Free Press.

32. Hastings G, Angus K \& Bryant C (editors) (2012) The Sage Handbook of Social Marketing. Los Angeles, CA: SAGE Publications, Inc.

33. Newton JD, Newton FJ, Turk $\mathrm{T}$ et al. (2013) Ethical evaluation of audience segmentation in social marketing. Eur J Mark 47, 1421-1438.
34. Carins JE \& Rundle-Thiele SR (2014) Eating for the better: a social marketing review (2000-2012). Public Health Nutr 17, 1628-1639.

35. Andreasen AR (2002) Marketing social marketing in the social change marketplace. J Public Policy Mark 21, 3-13.

36. Stead M, Hastings G \& McDermott L (2007) The meaning, effectiveness and future of social marketing. Obes Rev $\mathbf{8}$, 189-193. 